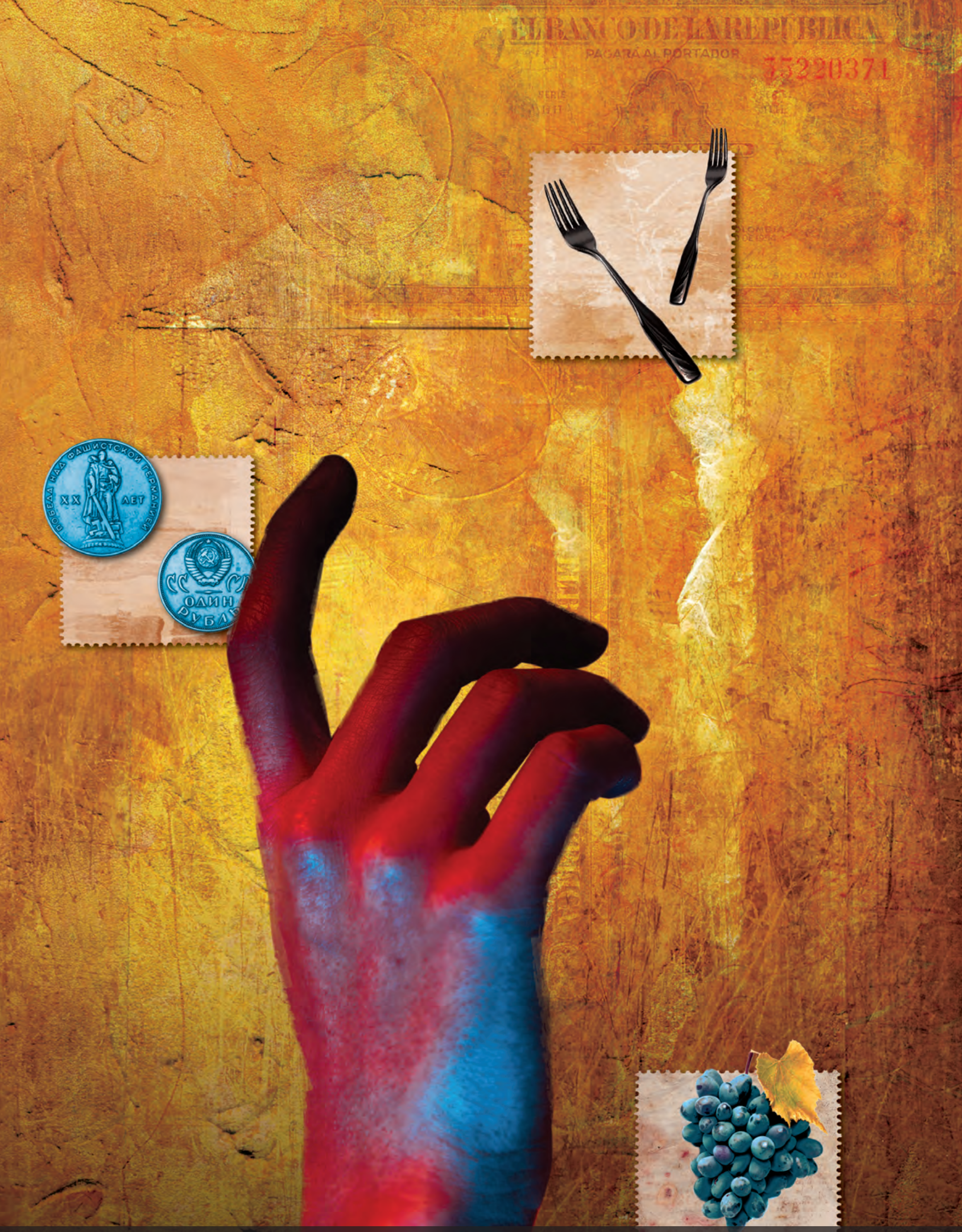

LA DIFICULTAD ENTRE LA CARIDAD Y LA FILANTROPÍA: UN ASPECTO A REVISAR EN EL MARCO DE LAS ACCIONES VOLUNTARIAS EN COLOMBIA 


\section{LA DIFICULTAD ENTRE LA CARIDAD Y LA FILANTROPÍA: UN ASPECTO A REVISAR EN EL MARCO DE LAS ACCIONES VOLUNTARIAS EN COLOMBIA ${ }^{1}$.

\section{Difficulty between charity and philanthropy: an aspect to review under the framework of voluntary actions in Colombia}

A dificuldade entre a caridade e a filantropia: um aspecto a revisar no marco das ações voluntarias na Colômbia

RECIBIDO:21 DEFEBRERODE 2016

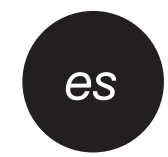

\section{RESUMEN}

El contexto colombiano se aproxima a grandes retos en el marco del posconflicto. Este artículo aporta elementos iniciales para una discusión de cara a la labor que muchas Organizaciones No Gubernamentales comenzarán a realizar con personal voluntario, debido a las ventajas económicas, sociales y profesionales que esta forma de acción humana produce. La caridad y la filantropía son aquí cuestionadas partiendo de evidencias históricas y de una apuesta por lograr un lazo social incluyente, garante de derechos y de deberes ciudadanos. Se revisan diversas producciones investigativas para concretar en preguntas clave para el reto que el Estado colombiano enfrentará ante la restitución del bienestar de víctimas directas y de poblaciones afectadas indirectamente por el conflicto armado.

\section{EVALUADO:26 DE SEPTIEMBRE DE 2016}

Evaristo Peña Pinzón (Colombia) evpena@uan.edu.co

Magíster en Psicoanálisis, subjetividad y cultura

Universidad Antonio Nariño

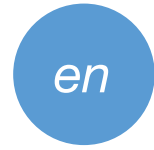

\section{ABSTRACT}

Colombia's context is about to face great challenges within the post-conflict framework. This article provides initial elements for a discussion about the work that many non-governmental organizations will begin to perform with volunteer staff, due to the economic, social and professional advantages that this form of human action produces. Charity and philanthropy are questioned here, departing from historical evidences and from a bet for achieving an inclusive social bond, guarantor of civic rights and duties. Diverse research productions are reviewed to concrete key questions regarding the challenge that the Colombian State will face for the restitution of the wellbeing of both direct victims and populations indirectly affected by the armed conflict.

\section{APROBADO:1DEJULIODE 2017}

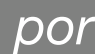

\section{RESUMO}

O contexto colombiano aproxima-se a grandes retos no marco do pós-conflito. Este artigo aporta elementos iniciais para uma discussão de cara à labor que muitas Organizações Não Governamentais começarão a realizar com pessoal voluntário, devido às vantagens económicas, sociais e profissionais que esta forma de ação humana produz. A caridade e a filantropia são aqui questionadas partindo de evidências históricas e de uma aposta por conseguir um laço social inclusivo, garante de diretos e de deveres cidadãos. Revisam-se diversas produções de pesquisas para concretar em perguntas chave para o reto que o Estado colombiano enfrentará ante a restituição do bem-estar de vítimas diretas e de populações afetadas indiretamente pelo conflito armado.
PALABRAS CLAVE: voluntariado, acción voluntaria, caridad, filantropía, posconflicto.
KEYWORDS: volunteering, voluntary action, charity, philanthropy, post-conflict.
PALAVRAS CHAVE: voluntariado, ação voluntaria, caridade, filantropia, pós-conflito.

PARA CITAR ESTE ARTÍCULO/TO CITE THIS ARTICLE/PARA CITAR ESTE ARTIGO:

Peña, E. (2017), La dificultad entre la caridad y la filantropía: un aspecto a revisar en el marco de las acciones voluntarias en Colombia. Panorama 11(20), 61-74

1 Este artículo es uno de los productos de la investigación interdisciplinaria "Diseño e implementación de un modelo de gestión del talento humano voluntario dirigido a algunas ONG de base en la ciudad de Bogotá D.C.", apoyado en su totalidad por la Universidad Antonio Nariño durante los periodos semestrales 2-2014 a 1-2016. Este sirvió como parte del marco teórico para luego proponernos una metodología de trabajo en función de mejorar las posibilidades de selección de voluntario y voluntarias para distintas ONG. 


\section{CONCEPTUALIZACIÓN DEL VOLUNTARIADO}

Si partimos de la complejidad, o incluso para algunos autores de la imposibilidad, de conceptualizar el voluntariado (Tavazza, 1995), encontraremos estancamientos que no favorecen el análisis de situaciones antecedentes, y mucho menos actuales, de los fenómenos solidarios, lo que impide la concreción de soluciones teóricas acordes con las necesidades inmediatas del vínculo social en el que vivimos, perdiendo inclusive la oportunidad de hacer uso de las ventajas vitales que el voluntariado comporta en toda labor humanitaria. En otras palabras: si no conceptualizamos, si no teorizamos, no es posible mantener algunas acciones organizadamente, mucho menos procesos y lineamientos que, a la postre, redundan en beneficios para el lazo social.

Así mismo, como lo proponen Mendoza y Quiroz (2009), en su trabajo investigativo sobre el estado de algunos aspectos del voluntariado en Colombia, se corre el riesgo de "caer en anacronismos y cometer errores de interpretación al pretender encasillar en una palabra ambigua una acción humana tan antigua, cambiante y compleja como la misma humanidad."

Esto nos lleva, irrevocablemente, a tener que dar un paso rápido y atrevernos a escribir teorizando, en aras de conseguir establecer las condiciones existentes y otras nuevas que den cuenta de este comportamiento humano. Así, el voluntariado, podemos entenderlo de entrada y sencillamente en tanto que "la voluntad de trabajar en función del bienestar de otros como propósito principal'.

Pero así lo que hacemos es condensar los diversos estudios y esfuerzos por conceptualizar alrededor de este aspecto de la labor humana. La salida a este impasse es, y seguirá siendo porque de lo que se trata es de seguir aportando claridades y discusión, atender a la historia y al mismo tiempo generar nociones, sin descuidar la elaboración que ya se ha realizado, ubicando los hitos que constituyen claridad sobre las mejores formas, las más acordes, con la realidad del momento, aquellas que se han generado para definir el voluntariado, las acciones, las organizaciones y los conceptos adyacentes al mismo.

Si nos referimos a la realidad contextual inmediata, podemos pensar inicialmente que definir 'voluntariado' implica complicaciones sustantivas, propias de nuestro contexto, a diferencia de otros lugares y momentos geohistóricos. No es así. Hace apenas treinta años, aproximadamente, viene consolidándose la discusión, el análisis y el debate alrededor de los distintos aspectos atinentes al voluntariado en Europa, especialmente en España, Alemania, Francia y Bélgica, entre otros países, en donde es evidente su estatus pionero y el avance que poseen en este tema (Mendoza, 2009).

Entonces, es para todos los contextos la dificultad, compartimos con los demás países, con las iniciativas institucionales y subjetivas, la complejidad de no tener una conceptualización clara y precisa, y sobre todo compartida, respecto al voluntariado y a todos los temas adyacentes. Al tiempo, debemos reconocer que los primeros pasos, y los más firmes, han sido dados tanto por algunos estados (países y sus instituciones), que han vivido verdaderas crisis transversales, así como por las organizaciones pioneras en temas humanitarios, y por ende su vigencia y su lugar paradigmático para el resto de los interesados.

Fundamentados en el estudio que tomamos como fuente inicial, respecto al voluntariado, encontramos la siguiente definición:

(...) Buscando en definiciones de algunos autores, se encuentra que al 'voluntariado' lo explican por las siguientes características: es de carácter solidario, es acción libre, no conlleva contraprestación económica, es una acción organizada. En la sociedad actual y según las interpretaciones, el rasgo que más identifica al 'voluntariado' es su carácter de gratuidad, y es comprensible el por qué estando sumergidos en una sociedad capitalista regida por los valores del mercado y el consumo, donde se promueven axiomas como 'el tiempo es oro', algo que se realice de manera gratuita, llama en demasía la atención (Mendoza, 2009).

La anterior cita proviene de diversos estudios, siendo los más relevantes los de Madrid (2001) y Tavazza (1995). En efecto, tanto la gente del común como el profesional promedio acudirán a conceptualizar al voluntariado, en nuestro contexto y en los foráneos, como algo que se hace con carácter de gratuidad, y siempre en beneficio de terceros que requieren de acciones solidarias para superar un estado de malestar o vulnerabilidad. La pregunta persiste respecto a las condiciones económicas de 
la contemporaneidad, pues la cuestión es: ¿quién está dispuesto a realizar una labor en beneficio de otros con el carácter gratuito de sus servicios? Esto nos lleva a pensar que los motivos que mueven a las personas que realizan labores voluntarias se dirigen a otro objeto, que no es el dinero y, así mismo, no necesariamente en las motivaciones 'conscientes' que muchos voluntarios pueden aducir.

Aquí existe una idea para abonar más terreno: hacen falta estudios sobre la motivación 'real' de aquellas personas que dedican parte de su tiempo, vida y recursos al voluntariado. Para tales efectos es importante recomendar que se aborde a 'las motivaciones' más allá de los estudios comportamentalistas, y se enfoque en las satisfacciones inconscientes que el voluntariado produce, por ejemplo en el narcisismo de quienes lo realizan. Esto puede ser objeto de otro trabajo, futuro.

Entonces, volviendo al tema, la Acción Voluntaria (AV), tiene más connotaciones que la gratuidad de la labor. La 'voluntad' de hacer un bien, incluida en el concepto 'Acción Voluntaria', es 'el espíritu' humanitario que atraviesa todas las acciones y la disposición para trabajar de esta manera. La solidaridad, concepto-acción que lleva a que el voluntario piense en su beneficiario, es la clave que las ciencias humanas plantean como pivote rector de la motivación de estas labores.

La condición, entonces, se configura de la siguiente manera: existe un voluntario que considera estar en capacidad de brindar algún tipo de beneficio, sea para un individuo o para una población en estado de vulnerabilidad estructural o momentánea. La condición del voluntariado implica que los últimos, los beneficiarios potenciales, requieran de la acción y participación de otros (profesionales o conocedores de algún arte o labor), para poder superar algunas situaciones denotadas como 'carencias sociales' (Mendoza, 2009). También puede ser que los voluntarios participen en la intervención y cambio de cualquier condición que esté aminorando el estado de bienestar ideal, y/o cuando existen condiciones de vulneración de derechos en individuos o grupos. El voluntariado, así, se constituye más allá de una labor gratuita, en una acción que parte de una motivación particular, subjetiva, que complementa los esfuerzos de varios actores sociales, o varios sectores, en marcos en los que es posible alcanzar objetivos colectivos mediante la inclusión del trabajo y la experticia de interesados e interesadas en aportar desde una intención humanitaria.

Podemos entonces describir las primeras particularidades del voluntariado para superar la idea exclusiva de 'gratuidad': es una labor realizada por alguien que posee una motivación (consciente e inconsciente, aun no explicada por quien realiza la actividad ni por quien la favorece desde las organizaciones), además de una clara intención o espíritu humanitario en tanto 'hacer un bien' a otro.

Con el último término debemos considerar que, principalmente, el interés que moviliza en mayor medida a las y los voluntarios se concentra en las situaciones de crisis humanitaria. Decíamos antes, situaciones 'estructurales o momentáneas', sean de naturaleza bélica, social, económica, política, educativa o de salud. Por ello siempre encontraremos al menos dos factores que se intersectan, que confluyen, para que el cometido de organizaciones gubernamentales o no gubernamentales desplieguen sus acciones, algunas de las cuales ocurren con la pertinaz colaboración de las y los voluntarios: un estado de vulnerabilidad individual, comunitario o social, y la intención humanitaria emergente a partir de la presencia del malestar, independiente de la existencia de un detallado diagnóstico del mismo.

Que exista un diagnóstico no es condición para comenzar las acciones. Incluso sin diagnóstico se acometen actividades de urgencia, debido a que determinadas situaciones lo exigen y ameritan. Véase las crisis de emergencias sanitarias, que si bien a la postre generarán un diagnóstico, en muchos casos requieren de acciones puntuales, como las medidas de contención, frente a problemáticas apenas identificadas, mientras el diagnóstico es realizado, por ejemplo. Este también sería un campo para aquellas personas interesadas en un voluntariado: ofrecer su 'saber hacer respecto a la evaluación y el diagnóstico', al tiempo que la asistencia incide directamente en las problemáticas mediante acciones específicas.

\section{CONTEXTO. LUGARES, SECTORES, DE DONDE PROVIENEN LAS ACCIONES VOLUNTARIAS}

Pasemos ahora a definir los lugares, 'sectores' en el léxico de algunos autores, desde los que provienen las acciones que se encaminan a solucionar las situaciones críticas
La dificultad entre la caridad $y$ la filantropía: un aspecto a revisar en el marco de las acciones voluntarias en Colombia 
de las comunidades. La definición más apropiada que encontramos es la que sigue:

(...) El Estado es conocido como el primer sector, la empresa privada, el segundo. En (el) tercer sector se agrupan asociaciones civiles, fundaciones, mutuales, cooperativas, clubes de barrio, sociedades de fomento, cámaras empresariales, colegios profesionales, comedores barriales y organizaciones religiosas, $\mathrm{u}$ organizaciones de la sociedad civil (...), (Mendoza, 2009).

(...) tercer sector en el que nosotros ubicamos la existencia de Organizaciones no Gubernamentales (ONG). Este sector está íntimamente ligado a las necesidades más inmediatas de los ciudadanos, y mediando un interés mayormente enfocado en el cambio, la transformación, de algunos procesos sociales, siendo lo último el pre-texto para la creación de dichas organizaciones. Al decir pre-texto queremos indicar el valor de texto previo al de la acción sobre el malestar, y la juiciosa ubicación de los objetivos que permite a muchas ONG definir su naturaleza de trabajo y las acciones que emprenderán puntualmente, así como su éxito y permanencia.

Podemos decir, entonces, que la organización, la agremiación ciudadana, informal o de índole más estructurada, siendo el último el caso de las ONG, depende del contexto en el que nace y de sus objetivos. Necesariamente encontraremos en las ONG una articulación y rigor de claridad frente a las condiciones particulares del Estado y frente a las necesidades específicas de los grupos humanos que tienen a su alcance. Por ende, las organizaciones que nacen en este sector no están desligadas de las condiciones del entorno social, ni de “(..) la relación con los demás actores de las realidades políticas, económicas y culturales" (Mendoza, 2009).

Esta idea nos obliga a ubicar en la historia las lógicas que permean las $\mathrm{AV}$ de antaño, lo que al mismo tiempo determina una ideología ${ }^{2}$ (Althousser, 1989), eficaz en nuestro contexto, diferente a lógicas anteriores. $\mathrm{Al}$ mismo tiempo, nos indica en dónde encontrar las sobre determinaciones dependientes de condiciones primarias de la AV. En otras palabras, es necesario remitirnos a la

2 Entendemos por ideología el conjunto de ideas de diversa índole, políticas, religiosas, que permiten una identificación de las personas con las acciones y con mentalidades, en acuerdo con una época o con un espacio geohistórico. Así, el concepto es más amplio y se debe considerar como el fundamento a partir de ideas que determinan las formas de pensar y actuar de individuos y grupos, ligados por procesos sociales y antecedentes culturales equivalentes. historia, de lo contrario se corre el riesgo, para la conceptualización y para los objetivos de las organizaciones dedicadas a cuestiones humanitarias, de estar desfasadas respecto a la realidad. Cuando se desconocen las condiciones económicas e históricas del lugar geopolítico donde se quiere incidir en pro del bienestar, se mantienen formas de AV que no son las más apropiadas. Esta es la importancia suprema de los aspectos históricos que permean conceptual e ideológicamente toda acción humanitaria. Para no redundar junto a los miles de estudios existentes sobre nuestro contexto colombiano (Granda, 1994), nos referiremos con exclusividad a un par de aspectos relacionados con el nacimiento del voluntariado en Colombia.

\section{EL NACIMIENTO DEL VOLUNTARIADO EN COLOMBIA. DOS ASPECTOS ESTRUCTURANTES Y DIFERENCIALES DE LAAV: LA CARIDAD Y EL ALTRUISMO}

Es evidente que una cantidad de organizaciones y personas se han enfocado en nuestro país para realizar acciones directas sobre el mejoramiento de las condiciones de bienestar y vida de las poblaciones que, identificadas focalmente respecto a determinados temas, necesitan del apoyo de un tercero que venga en su auxilio, sea por condiciones de necesidad socioeconómica, o por ser víctimas de sometimientos, marginalidad y exclusión ${ }^{3}$.

Debido a la tradición cultural colonial y postcolonial de nuestro país, muchas instituciones de AV tienen el rasgo de operar desde la caridad, con una marcada incidencia de la institución religiosa. Las formas más recientes de organización caritativa tienen como característica ser independientes de ámbitos políticos, es decir, fuera de intereses gubernamentales y partidistas. Sin embargo, es bien sabido que el nacimiento de estos esfuerzos dependió de las formas feudales, monárquicas y eclesiales de la edad media. En los periodos llamados conquista y colonia, en lo que atañe a nuestro país, es evidente que el mayor esfuerzo lo propusieron las misiones religiosas, administradas y revisadas por 'la corona española', y se puede considerar dicho esfuerzo como $\mathrm{AV}$ en tanto que

\footnotetext{
3 Un ejemplo fehaciente actual son los esfuerzos que hacen algunas organizaciones que engloban a otras tantas dedicadas a actividades humanitarias. Para un bosquejo inicial recomendamos la visita a páginas de internet tales como http://ccong.org.co/ccong/, http:// mesadearticulacion.org/, http://www.ong-ngo.org/es/, http://www.oas.org/es/, http://www un.org/es/ecosoc/, http://www.iadb.org/es/paises/colombia/colombia-y-el-bid,1026.html, que muestran un panorama de las diferentes iniciativas, lugares y sectores interesados en cambios de situaciones identificadas en el país y la región. Es evidente que además que los esfuerzos nacionales están disgregados o no son de fácil adquisición en cuanto a acceso de información, por ende resultan de difícil visibilidad para el investigador o interesado en la temática.
} 
sus acciones eran sin ánimo de lucro, sin costo para el beneficiado y con una clara intención de beneficio para las gentes, claro, con la motivación de alcanzar más creyentes en su redil (Mendoza, 2009).

Si nos permitimos una digresión para aclarar qué traduce 'caridad' en el contexto occidental es más que conveniente referirnos al profundo trabajo realizado por Le Brun (2010). El autor propone que es el intento de la iglesia católica, aprovechando los acontecimientos cotidianos de una determinada época, por obtener la atención de una buena cantidad de población. Lo que subyace en la caridad es la trasmisión de una enseñanza, la de la realización de actos supuestamente desinteresados, en los que el 'buen católico’ no debe pensar en su condena, o su perdón, como principales motivos de su acto, lo cual debe llevarlo a un simple 'hacer el bien'. E1 impactante trabajo de Le Brun indica que es posible articular esta enseñanza con la metáfora, proveniente de la leyenda del 'pregón' realizado por una mujer, que andaba por las calles en situación harapienta, propugnando a los cuatro vientos, con una antorcha en una mano y un cántaro en la otra, que ella prefería alcanzar los cielos y quemarlos, haciendo lo propio con el infierno, enfriándolo mediante la inundación que produciría, antes de hacer cualquier cosa motivada por el temor de lo que sucedería después de la muerte. Delicada postura frente a un monoteísmo afincado en la creencia acrítica, pero magistralmente usada por los padres de la iglesia, lo que permite que la imagen de 'la caridad' ande todavía entre nosotros con muchas formas cotidianas de hacer el bien sin el interés de obtener beneficio propio.

Este llamado místico fue escuchado y tomado como referencia por occidente, al punto que se convertiría en el paradigma del comportamiento ideal respecto a la pureza de las intenciones de quien busca la identificación con aquel que 'hace el bien'. La consecuencia es: 'hacer el bien sin esperar nada a cambio'. Es una cuestión bien singular, pues caben las preguntas: ¿qué ganancia subjetiva queda a quien procede de esta forma? ¿Cómo se tensiona el bien del otro con la pérdida para quien ofrece el bien? ¿Estamos, hablando de la caridad, en una estructura en la que existe 'ganancia' contra 'pérdida’? ¿Qué aporta el misticismo al tema de la caridad, y de aquí al de la voluntad de hacer el bien? Lo claro es que la caridad se forja como el elemento rector que hace del amor eclesial uno que indica pureza, uno ausente de intenciones tras su acto. Al mismo tiempo indica la problemática que un Francisco de Asís denunciara: los intereses económicos y políticos de un modelo eclesial cada vez más firme y que aprovechaba la figura de la indulgencia para obtener sus recursos piadosos (Larragaña, 1981).

En fin. Las condiciones de la historia de la humanidad, y en ella la historia occidental con su iglesia judeocristiana, denotan ideales y acciones específicas que alcanzan a permear todo el mundo occidental, y mucho más el previo al momento histórico de la colonización de América.

Los procesos sociales, profundamente afectados por las lógicas de los conquistadores y colonos, perturbaron directamente a una población que poseía un andamio social totalmente diferente. Las sociedades indígenas sufrieron entonces profundas mutaciones a causa de la férrea posición monárquica, feudal y monoteísta. Esto no es una deducción, de ello existen las más pesadas evidencias obtenidas en los datos de historiadores, antropólogos e indígenas de la época. Lo que sí se deduce es la forma de organización social antecedente a la conquista y la colonia (Espinoza Soriano, 1980), que era radicalmente diferente a las condiciones de las nuevas formas importadas de Europa, generando secuelas que aún hoy se viven en el territorio nacional, comenzando por serios desórdenes demográficos, evidentes en aquella época, y hoy también, en una natalidad decreciente de la población indígena, así como una veintena de enfermedades 'incurables, intratables', traídas de ultramar (Mendoza, 2009), todo asociado a los cambios sociales obligados por la cultura monárquica que se impuso con la conquista y la colonia.

Las condiciones de transacción económica cambiaron, lo que degeneró en pobreza, a niveles paupérrimos, de la población nativa, debido no solo a los impuestos obligantes de la corona española, sino a todo el andamio económico que imponía la explotación y expropiación de bienes y territorios de los indígenas, esto unido al cada vez peor estado de salud de poblaciones completas.

El empobrecimiento de los indígenas se hizo manifiesto como consecuencia de la ocupación, la imposición de impuestos y los sistemas de explotación laboral. Por otro lado, la población blanca también sufrió de marginación; hubo quienes no llegaron a tiempo para el reparto de tierras o quedaron
La dificultad entre la caridad y la filantropía: un aspecto a revisar en el marco de las acciones voluntarias en Colombia Colombia 
muy aislados, lo que se tradujo en últimas en empobrecimiento (Mendoza, 2009).

El lugar que asumió la asistencia social fue, justamente, compensar en parte los estragos de la ocupación española. La asistencia social, que ya reconocía cómo Occidente operaba en aquella época, se movió a América para 'prevenir, remediar o erradicar' las dificultades propias del proceso colonizador. Entonces, ella “(...) se desplazó hacia Hispanoamérica durante el proceso de colonización como parte de lo que se denominó proyecto civilizador que se afirmaría en la fundación de ciudades" (Restrepo, 2006).

Los ideales occidentales se trasladaron junto con las formas de administración propias de la época. Y la motivación de la acción social era clara: ser parte del proceso civilizador, es decir, cristianizante. Así fue como las primeras AV llegaron a América, para generar mejores oportunidades a los evidentemente menos favorecidos por cuenta de la novedosa imposición de interacción social, en la que quien puso las condiciones fue el colonizador. De aquí en adelante queda clara la relación que nace, y se alimenta hasta nuestros días, entre el poder gubernamental, sea cual sea, y el clero, siendo el último el que asumirá transmitir las 'mejores formas de comportamiento individual y social', condiciones del lazo social occidental determinadas desde la moral, el bienestar y el salvamento del alma. El poder civil, regido por los ideales de la religión, se establecerá como uno que sustentará sus alcances en la negociación que haga con la iglesia: "El uso de la doctrina católica para la regulación de las relaciones sociales, se manifestó con fuerza desde el comienzo y se estableció así una alianza entre los poderes civil y eclesiástico en la que mutuamente se vigilaban y complementaban" (Mendoza, 2009; Restrepo, 2006; Restrepo, 1997).

Entonces, el primer movimiento importante de AV en nuestras tierras estuvo determinado por la coyuntura de la colonización, y en función de alivianar la pobreza y las enfermedades, aspectos importantísimos para la discusión científica, eclesial y política en la Europa de aquella época (Mendoza, 2009). La contrarreforma también tuvo que ver en lo que surgió como $\mathrm{AV}$, pues se intensificó la visión medieval de las razones de 'ser pobre', así como su lugar 'privilegiado' en tanto que se idealizó la pobreza articulada a tener 'mayor posibilidad de llegar a la otra vida con la seguridad de un espacio en el cielo'. acudieran a la 'caridad', usando la condición del pobre o desvalido como puente entre este mundo y sus aspiraciones de salvación. De nuevo se revelan 'motivos' de quien hace caridades. El sufrimiento, entonces, cumplía en la mentalidad de la época una función de organización del lazo social que permitió, entre muchas formas de acción, la del voluntariado:

(...) Así se reafirmaron los principios que sustentaban la asistencia a los pobres como un deber del buen cristiano. Esta virtud la caridad- es la que define las actitudes teóricas y prácticas de la asistencia social en los primeros años de la colonia, además porque el pobre o el que de alguna manera sufriera era considerado un puente natural entre el hombre y Dios. (Mendoza, 2009)

Este puente es fundamental, no solo en aquella época, sino en la mentalidad de quienes hacen voluntariado con ideales caritativos en la actualidad, pues con ello establecen un puente directo con sus creencias. La identificación del malestar del pobre o desvalido cumple la función de ubicar en ese lugar el medio para llegar a un semblante de misticismo (no el misticismo en sí), que genera una relación supuesta directa con Dios. Considerarse buen samaritano, buen cristiano caritativo, era un valor excelso para la mayoría en aquella época, y sigue siéndolo para muchos, especialmente para quienes en aquel momento se consideraban parte de una clase favorecida social y económicamente. Así, la iglesia con sus misiones, se convirtió en objeto de una observación exigente, tanto por el poder gubernamental como del civil, creando una primera tensión en lo que respecta a los ideales de la $\mathrm{AV}$ :

(...) Las llamadas obras pías -obras de caridad-,entre las que se contaban hospitales, casas de hospicio, casas de recogidas, entre otras, eran casas de redención de bienes y caudales de los vecinos para "asegurar" su salvación, aminorar las penas del purgatorio y alcanzar el beneficio de la gloria eterna (...) Las gentes pudientes "hipotecaban" a favor de la obra -le daban dinero y bienesademás de diezmos autorizados por real cédula. A cambio, los beneficiarios de estas obras elevarían súplicas a favor de su benefactor (...) (Mendoza, 2006)

Cosa que a los ojos de muchos no era bien vista, pues implicaba que grandes cantidades de dinero se empleaban en los menos favorecidos, sin oportunidad para que interesados en obtener una parte de dichos recursos los 
vieran siquiera. En otras palabras: ver que el recurso es invertido en los menos favorecidos siempre ha levantado ampolla. Esto cambiará con rapidez: la inversión de los recursos, conforme las ideas de la monarquía se van especializando e instalando de manera diferente en la continuidad de la historia, debido al canje de familias en el poder, será evidente al punto de que las intenciones y las decisiones del direccionamiento de los recursos se dirigirán hacia otros objetivos, por ejemplo hacer la guerra.

Las primeras obras realizadas en estas condiciones, caritativas, fueron hospitales, que dedicaron su labor a la atención de indígenas contagiados con enfermedades europeas. Los espacios eran sobrios y con un claro objetivo de recogimiento, todo de acuerdo con los ideales medievales de devoción frente al santo patrono al que se encomienda el buen morir del enfermo (Restrepo, 1997; Restrepo, 2006). Es claro que el ideal que atraviesa el 'bien hacer' para las personas que hacen parte de las misiones hospitalarias está determinado por las condiciones de humildad, en ocasiones de humillación, de individuos o poblaciones enteras en el lugar de la miseria, de la enfermedad y en últimas de la muerte. El enfermo, representando la tragedia cristiana, será el objeto predilecto para estas acciones de caridad: es identificado con Cristo, y con los cristianos sacrificados por los más poderosos en diferentes momentos de la historia. Es un ambiente perfecto para lograr una incidencia importantísima en las gentes vulnerables y modificar sus esquemas de creencia: mostrarles que son idénticos al personaje en el que el colonizador, benefactor en este caso, cree (Cristo), y que por ello le atiende caritativamente. Así, se fundaría en nuestro territorio un hospital importante en cada ciudad que tuviera presencia de una cédula o encomienda real, sea dicho que se fundarían por cuenta de los 'hermanos hospitalarios' con dineros donados y con personal exclusivamente religioso ${ }^{4}$ (Forero, 2009).

El asunto de la salud no fue el único que la asistencia social de la época intervino. Los otros dos grandes temas en los que se prestó especial atención fue la situación de niños expósitos y de mujeres adúlteras ('recogidas', se las llamaba), ambos síntomas sociales de una organización plenamente machista y patriarcal. Los niños abandonados eran cuidados con dineros provenientes de

4 Ciudades como Tunja, Pamplona, Cartagena y Popayán fueron las primeras en vivir esta iniciativa en el territorio nacional. donaciones, pero también de diezmos que eran cobrados a indígenas, aunque estos eran recursos de menor cuantía que el exigido para colonos o criollos. El asunto de las mujeres 'recogidas' posee varias hipótesis que merecerían algún trabajo investigativo, pero se puede deducir que se trataba de mujeres que no soportaron en un determinado momento, o por alguna circunstancia, las condiciones (del maltrato) propuestas en el lazo social:

En 1639 por Real Cédula procedente de la Corte se autorizó la fundación de la Casa de niños expósitos y mujeres recogidas. La constitución de la casa autorizaba para su sostenimiento la séptima parte de los diezmos que los indígenas debían dar a sus iglesias y hospitales. La Casa se abrió en diciembre de 1642 y allí cuidaron niños abandonados y sacaron de circulación mujeres adúlteras. Los niños eran custodiados por amas de cría que recibían salarios por su labor. En este campo la caridad tuvo otra connotación, pues claramente se asistían necesitados, pero también se ejerció control social desde los valores católicos. La acción se fundamentaba en la caridad cristiana, que articulaba la protección de la infancia, el control y la sanción a las mujeres que se resistían a los abusos del poder paterno o marital (Ramírez, 2006).

Queda una vez más evidente que los ideales de la época estaban determinados por la incidencia de las ideas religiosas, morales, y de los ideales de control social imperantes.

En el caso de los niños se tratará de la primera acción social que permitiría posibilidades de supervivencia y de lograr, con alguna dignidad, una crianza primaria, sin que ello asegurara, de ninguna forma, movilidad social ${ }^{5}$ (Bourdieu, 1984; Crompton, 1994; Wright, 1983). En el caso de las mujeres era más una acción para 'sacarlas de circulación', acaso para que los traumatismos vividos por ellas no se replicaran, deteniendo también su victimización, en perfecta concordancia con lo dictado por la religión católica respecto a los lugares ideales de las

\footnotetext{
5 Reconocemos que el término 'movilidad social' es extremadamente reciente. Proveniente de la sociología, y de las discusiones del derecho político, indica las posibilidades que tiene un individuo o un grupo de hacer cambios en su ubicación socioeconómica en un espacio-tiempo determinado. Se reconoce que la estratificación social y económica determina la ubicación de los individuos y sus posibilidades, y las condiciones políticas y sociales, así como individuales, serían los motores de cambio y posibilidad de movilidad, sin que esta sea idealmente 'hacia arriba'.
}

La dificultad

entre la caridad y

la filantropía: un

aspecto a revisar en el marco de

las acciones

voluntarias en

Colombia
| Panorama

| pp. 61-74

Volumen 10

| Número 20

| Enero-Junio

| 2016 
Evaristo Peña

Pinzón | ideales de maternidad, cuidado de los otros y extremo recato, so pena de ser consideradas herejes, blasfemas y/o cortesanas. Si bien estas son interpretaciones y deducciones realizadas a partir de varias reflexiones de diversa naturaleza, no será raro encontrar documentación que así declare el lugar de las mujeres en el medioevo y en nuestro territorio durante la colonia.

El cuarto tema ${ }^{7}$, no menos importante y bien determinante de las AV y su historia fundacional, es lo que algunos clérigos asumen como su función de defensa y protección de la dignidad humana de la población diferente, indígena o de las negritudes. Fray Bartolomé de las Casas, Pedro Claver, entre los más reconocidos, denunciarán, llamarán la atención, incluso se arriesgarán social y vitalmente, para que la dignidad de los indígenas y de las negritudes sea restituida a la luz de lo asumido como mandato divino: los hombres son hermanos a los ojos de su padre, Dios.

Fray Bartolomé realizará un movimiento que signará histórica y geográficamente al pueblo mexicano, logrando que sus ideas traspasaran fronteras y que varios simpatizantes se le unieran en pro de generar respeto por los 'naturales'. Pedro Claver se encargaría de evidenciar los vejámenes sufridos por las negritudes $\mathrm{y}$, al mismo tiempo, enviaría con mensajeros sus ayudas asistenciales en la forma de ropas, medicinas y alimentos, a aquellos que identificaba como necesitados.

Se podría pensar que se trató de esfuerzos personales, sin embargo (...)

(...) Bartolomé de las Casas y Pedro Claver no fueron actores individuales en

Panorama |

pp. 61-74|

Volumen 10 |

Número 20 |

Enero-Junio |

2017 |

6 Recordemos que la devoción de las mujeres debía ser mayor, más ferviente, hacia Dios y los santos, y en segundo lugar a sus padres, en particular al padre, y luego a 'su señor', su esposo. La organización patriarcal todavía era una cuestión vivida en aquella época, y por ende el lugar de la mujer como objeto de transacción simbólica entre hombres y linajes, independiente del poder económico o social, estaba en ese lugar en lo social. Por tanto, cualquier contravención a este orden podía generar ser considerada como afrenta al orden establecido, lo que hacía que la exclusión del lazo familiar fuera posible y no poco frecuente.

7 Recordemos, hasta aquí hemos hablado de los enfermos, luego de los niños expósitos y de las mujeres de dudosa afiliación familiar, 'recogidas'. un trato humano para las poblaciones sometidas, claro está que dentro del marco de conversión y evangelización que la iglesia tenía durante aquella época (Mendoza, 2009).

Hasta aquí es evidente el poder de la iglesia, el cual empezó a verse diezmado desde 1760, aproximadamente, con las reformas borbónicas, las cuales, apoyadas en las ideas de la Ilustración francesa, les quitó poder económico y social a los representantes de la iglesia. El principal objetivo de la reforma gubernamental era obtener más impuestos, lo cual se lograría liberando a los creyentes de su pago en la iglesia, y llevando ese dinero a las arcas del gobierno. "Esta iniciativa se tradujo más precisamente en que a la iglesia se le quitaron sus potestades compartidas con el Estado, menos la administración de las obras pías, sus grandes fortunas también fueron expropiadas y, los jesuitas fueron expulsados" (Mendoza, 2009).

Los cambios de las políticas gubernamentales profundizaron cambios sociales, y con ello también las prácticas de $\mathrm{AV}$, antes en manos exclusivamente de religiosos.

\section{EL PASO CRUCIAL, CUESTIONAR LA CARIDAD YEL ALTRUISMO}

Luego de la reforma nace la figura del 'hospicio', que operará en función de cuidar del vulnerable (niños, mujeres, indígenas, negritudes, pobres), pero ahora su visión es diferente a la de la caridad cristiana en dos factores. Primero, ya no es la ayuda en función de la igualdad, la hermandad a los ojos de Dios y, segundo, la ayuda ya no tiene como motivo encontrar apertura de las puertas de la salvación para el caritativo. Ahora el centro de las labores está enfocado en la 'dignidad humana': la filantropía en vez de la caridad. Los ideales filantrópicos, encauzados hacia los pobres, por ejemplo, no tenían, ni tienen, distingo alguno más que la condición de vulnerabilidad, que se vuelve en la meta a superar.

El otro aspecto que cambió fue el objetivo intrínseco de las AV: mientras la caridad tiene la doble función de generar bienestar pasajero en el vulnerable, manteniéndolo en la misma condición, y abrir las puertas de la tranquilidad de la conciencia del caritativo, la filantropía se propuso 'formar' para educar y hacer productivos a sus beneficiarios: lograr la autonomía de los 
últimos. Mientras la caridad era connivente con las desigualdades, y las mantenía, la filantropía se propuso un marco de acciones que permitiría equivalencias sociales, disminuyendo las brechas entre individuos y clases ${ }^{8}$ (Mendoza, 2009). Es así como, hacia el final del siglo XVIII, se establecerá una de las primeras instituciones con una claridad filantrópica, oponiéndose a la caridad de la época: La Misión de los Montes Píos, institución en la que se asumirá el cuidado y protección de viudas de guerra y huérfanos (Mendoza, 2009), con una visión filantrópica, inicialmente en España.

Otro notable, de entre los escasos ejemplos, es el de María Clemencia Gertrudis de Caycedo y Vélez, viuda con herencia, quien se propondrá fundar el primer colegio femenino de la ciudad, "La Enseñanza”, en 1783. Este colegio era para niñas y jóvenes provenientes de familias acaudaladas, pero su benefactora dispuso que existiera un aula para que las niñas pobres asistieran (Mendoza, 2009). El anterior es el claro ejemplo de ese objetivo de combatir las brechas generando oportunidades sociales, para que la autonomía de los sujetos y las familias, y así lo social, lograran un cambio fehaciente, real, en autonomía. Indistinto de los motivos personales de doña María Clemencia, lo interesante es el aporte para que la movilidad social se dé en niñas y mujeres que con poca o nula posibilidad de educación logren un cambio.

Nos preguntamos: ¿caridad? ¿Altruismo? ¿Filantropía? Si recordamos lo dicho arriba, el problema planteado nos lleva a la sin salida de las motivaciones reales de un individuo, lo que nos indica el narcisismo y el egoísmo en el centro de sus acciones. No entraremos de nuevo en esta discusión, que tiene tanta historia como producción importantísima, que amerita su detenida revisión (Stiefken, 2014). Solo tomaremos un elemento fundamental para lograr la distinción: el lugar lógico del beneficiario. En la caridad sabemos que el sacrificio, el valor sacrificial del 'objeto' del acto caritativo se mantiene en tanto tal. En el altruismo se quiere un cambio en el objeto. Así, el paso crucial de una forma a otra está dada por las condiciones en las que se asume al objeto, desde el principio, en tanto 'fin' del cambio, y no como receptáculo de ayuda pasiva e inamovible.

8 Por eso resulta interesante esta revisión, pues la movilidad social, aun sin ser conceptualizada, se convierte en un objetivo que en este marco se evidencia como parte de lo que el Estado de la época se propone, aun si los fines que proyecta son más económicos que humanitarios, pues más personas productivas son menos carga inmediata y a posteriori.

Las ideas de la filosofía sobre la naturaleza de la conducta humana, léase la dicotomía entre las posturas de Hobbes y Hume, son aquí esenciales para comenzar una discusión, además porque son contemporáneas de las primeras acciones voluntarias que emergieron en contextos de necesidad política y civil, específicamente en contextos en los que la guerra promovió el desamparo de muchos, especialmente los más vulnerables.

Haciendo una reseña somera, muy superficial, podemos afirmar que la idea de Hobbes es la de que el egoísmo es fundamental en la naturaleza humana y así mismo afecta su conducta, con lo cual cuestiona la supuesta 'naturaleza social' del humano. Si esto es así, entonces un ser humano que se interesa en la agremiación lo hace por un interés propio, particular, no por benevolencia con los demás, no por caridad. Hobbes es así un 'moderno', en la medida en que rompe con las ideas clásicas, tanto griegas como judeocristianas, de que el hombre está ya preparado para la sociedad al cuestionar que sus intereses egoístas demuestran que la sociedad es una construcción, una ficción y por ende no son propias de la 'naturaleza' humana.

Así podemos leer lo que el autor propone:

El hombre por naturaleza [...] le molesta la soledad prolongada $[\ldots]$ por eso no niego que los hombres tiendan por naturaleza a asociarse unos con otros. Pero las sociedades civiles no son meras agrupaciones, son alianzas, y para conseguirlas son necesarias las lealtades y los pactos (Hobbes, 1642/1984).

El autor indica con ello que si bien es molesta la soledad, solo se busca la asociación para fines egoístas, que pueden terminar siendo comunes, en la medida en que existan lealtades, pactos: acuerdos. "[...] no buscamos pues por naturaleza compañeros, sino obtener de los demás honor y comodidad" (Hobbes, 1642/1984).

Sin embargo, Hobbes no es extremista: confía en todo caso en que 'algo del ser humano' puede llevarlo a ser un buen ciudadano, es decir a que puede comportarse de manera gregaria, en busca de un bien común: un egoísmo inteligente. Esta posición, concluirá el autor, solo sirve para explicar algunos fenómenos sociales, políticos y económicos, siendo el valor fundamental de

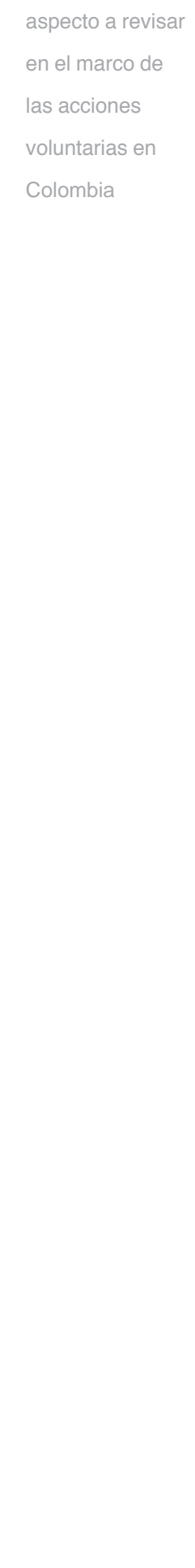


su propuesta que el individualismo será un factor a tener en cuenta en adelante para cualquier situación gregaria.

Evaristo Peña

Pinzón |

El caso de Hume, posterior a este primer coqueteo de Hobbes con el desprendimiento de la caridad por cuenta del individualismo, es diferente, pues con este autor se plantean los recursos a los 'buenos sentimientos'y al altruismo. Para Hume el altruismo, la capacidad de sentir en benevolencia por el otro, es una condición humana natural, lo que hace que se oponga radicalmente a la propuesta de Hobbes. El primero afirmará sus postulados sobre la base de que existe un equívoco en la teoría de Hobbes por cuanto, si existe un amor egoísta, es porque este es uno que se volvió al revés de su naturaleza, mediante un giro favorecido por la imaginación y reforzado por una variedad de apariencias (Hume, 1742/1993).

Si esta posición se sostiene en la teoría de Hume es sobre la base de que el humano 'debe' constituir su comportamiento alrededor de la virtud y en contraposición con el vicio, lo que delimita su marco de incidencia: una moral en la que cooperan la razón y los sentimientos: la razón puede enfrentarse a situaciones concretas y a sacar ideas basándose en los hechos, mientras que si se trata de una 'acción' se debe contar con los sentimientos, y específicamente unos benevolentes cuando se trata de una 'buena acción', una que esté en el marco de la moral ideal, utilitaria.

Stiefken (2014), en su tesis doctoral, trayendo a los autores recién nombrados, afirma que estos se basan justamente en el sujeto de la acción, y no se plantean la naturaleza del objeto. Si lo pensamos desde esta perspectiva, apoyados un poco en otras teorías (el estructuralismo y el psicoanálisis son buenas herramientas), encontraremos que el objeto, la calidad de este, y lo que se lo quiere (en ambos sentidos, cómo y para qué se lo quiere) es lo que despeja la condición diferencial, que nos permite definir que un paso adicional es el dado por la filantropía, que desea en su objeto un cambio. Un cambio que admite la independencia del objeto y su momentánea, no permanente, condición de vulnerabilidad. La pregunta aquí planteada es: ¿cómo se logra el cambio de un objeto a otro, dar el paso de un objeto caritativo a un objeto filantrópico?

La propuesta, tanto de Hobbes como de Hume, se cae en el egoísmo inteligente o en el altruismo utilitario las condiciones para que la humanidad realice acciones 'buenas', pues no es cierto que la naturaleza bondadosa sea algo compartido por la especie; es preferible pensar y analizar la situación particular de la relación que se establece entre un sujeto supuesto altruista con otro, $y$ con otro, lo que genera serie y al mismo tiempo diferencia, pues, si bien el sujeto se supone 'es el mismo', no existe repetitividad en dichas relaciones. La pregunta que proponemos es qué permite a cada sujeto asumir una determinada postura en función del objeto, y así la pregunta es por la lógica del cómo un sujeto supuesto altruista establece una relación especial con su objeto beneficiario.

\section{QUÉ POSIBILIDAD PARA LA PARTICULAR PAREJA DEL SUJETO SUPUESTO ALTRUISTA Y SU OBJETO BENEFICIARIO}

En este punto tenemos que ser consecuentes: no existe un acto totalmente desinteresado. Los vínculos sociales se forjan por intereses comunes, pero ellos implican renuncias pulsionales, y las más de las veces esta se forjan en la vía del abandono del deseo de aprovechamiento que se quiere realizar del otro. (Freud, 1927/2004; Freud, 1930/2004).

Cuando Freud comienza a revisar los intríngulis de la cultura se encuentra con que, mediante las organizaciones, y en especial las religiosas, intentamos atemperar nuestras pulsiones y generar, en lo posible, acciones benéficas para la vida en civilización. Sin embargo, nada asegura que exista la buena forma, por el contrario, es la incidencia del deseo lo que genera esa propensión a la transgresión, esta sí natural en el ser humano en contraposición con la cultura. Mientras la pulsión se deriva hacia la satisfacción, sin importar las consecuencias ni para el sujeto ni para el objeto, la ley, las normas, vienen en el lugar de establecer las obligaciones mediante las cuales instauramos condiciones para no matarnos entre nosotros.

Las organizaciones religiosas de occidente, sustentadas en ideas grecorromanas, no dejaron de pensar en el bien absoluto, y de allí su recorrido histórico moral hasta nuestros días.

Freud cuestionará la idea judeocristiana de amar al prójimo como a sí mismo, indicando la imposibilidad de 
esta condición porque básicamente el otro, el objeto, está en una posición en la que cada sujeto desea, más que otra cosa, sacar provecho de este. Entonces el amor como ideal judeocristiano en la teoría freudiana se cae por su propio peso.

Antes de entrar de lleno en una situación pesimista, en este punto Freud lo es y con toda razón como espectador de la gran guerra, y para el momento en que escribe "El malestar de la cultura" y "El porvenir de una ilusión" el preludio del holocausto nazi, podemos con esto cuestionarnos cuál es la naturaleza de la relación que el sujeto supuesto altruista le plantea al objeto.

Las ganancias que debemos suponer, y que de hecho encontramos en el sujeto supuesto altruista son narcisistas. Esto quiere decir que la satisfacción obtenida está dirigida a completarse en la imagen con el objeto beneficiario: no existe una completitud satisfactoria, en lo imaginario, en el sujeto supuesto altruista de no ser con la existencia del objeto beneficiario. Así, el segundo se convierte en el soporte del primero. Esto es un riesgo, porque se puede conminar a que el objeto permanezca tal cual, para complacencia del sujeto.

Por otro lado, en el caso de las AV el objeto beneficiario cumple la función en tanto que 'nebenmenchs". En la teoría freudiana el complejo de vulnerabilidad es el iniciador de la civilización siempre que exista un adulto que sepa hacer las cosas con el pequeño bebé, al cual se le indican las condiciones, límites, posibilidades, para que la pulsión y sus destinos se acomoden a lo que la contraparte desea (Freud, 1950/, 2004). Esta condición es la que debemos pensar muy detenidamente, porque aquí lo que encontraremos es una repetición en la situación de vulnerabilidad vuelta a sentir en posición de víctima del conflicto, y con ello la posibilidad de generar dependencias importantes con la persona que asume los cuidados, el sujeto supuesto altruista.

¿A quién le corresponde aquí la responsabilidad? A quien es demandado en calidad de sujeto, que deberá ingeniárselas para que su contraparte, el objeto, pase a una condición de deseo, saliendo de la forma de dependencia en la que se encuentra. Si bien parece que allí lo que existe es magia, en realidad solo una posición ética

9 Complejo de dependencia, de vulnerabilidad, que se repite desde la condición neonatal del ser humano hasta su despliegue en cualquier situación que produzca angustia. lo logra: el sujeto supuesto altruista debe saber que él mismo está en falta, que él, como cualquier otro, puede favorecer algunos procesos, entonces que no es más especial que otros y que el objeto beneficiario debe dar el paso hacia otro lugar.

La caridad, el amor al prójimo judeocristiano, así, no tiene posibilidades de lograr mayores resultados, a menos que su posición ética obligue a que la relación esté destinada a romperse, a cambiar, a no ser obligatoriamente asistencialista, ni permanente, ni constante.

\section{LA INCIDENCIA HISTÓRICA Y LA CONTEMPORANEIDAD: EL RETO DE TRABAIAR VOLUNTARIAMENTE CON VÍCTIMAS DEL POSCONFLICTO}

A pesar de que se intenta aquí un salto categórico importante, a manera de conclusión proponemos para cerrar este escrito pensar la contemporaneidad del voluntariado en Colombia, de cara al proceso de posconflicto que se avecina, sin desconocer la incidencia histórica, y teniendo como marco el problema conceptual, sus derivaciones claramente de antaño y otras posibilidades para pensar la pareja sujeto supuesto altruista y el objeto beneficiario.

Los ritmos de los procesos sociales, masivos y estructurados de manera más limitada, no responden a las condiciones históricas que los investigadores podrían proponer. Esto quiere decir que no necesariamente con la llegada del cambio político y gubernamental, que conllevó transitar de una monarquía a una república, se modificarán los modelos de acción, pensamiento y organización humanos. En ocasiones se mantienen usos y hábitos, así como pretensiones comportamentales sustentadas en posiciones morales ya decaídas, pero eficaces en la ideología y mentalidad de algunas personas e instituciones, y para desventaja del lazo social son las acciones negativas las que se mantienen: este es el caso de un Estado como el colombiano, en el que la corrupción es una de las condiciones que todos los nacionales reconocen, de una forma u otra, alcanzando e influyendo todo aquello que puede hacerse en lo social, lo cual es aprovechado por algunos dedicados al trabajo humanitario para generar productividad económica, sin importar los verdaderos cambios esperados en las poblaciones a quienes se dirige la labor.
La dificultad entre la caridad y la filantropía: un aspecto a revisar en el marco de las acciones voluntarias en Colombia Colombia
| Panorama

|pp.61-74

| Volumen 10

| Número 20

| Enero-Junio | 2016 
La historia de los españoles que llegaron al territorio, más las dificultades sociales, todo asociado o relacionándose con la corrupción de esos días, seguramente, como muchos otros factores, permeó al vínculo social al punto de generar diversos estratos de contrabando, en los que nativos, criollos y españoles propendían por su propio interés: se forja un egoísmo que imposibilita las pretensiones morales hobbesianas. Si algo realmente se ha opuesto para lograr lazos pacificantes y acciones en justicia no es otra cosa que el interés individualizado, en función de obtener ganancias a como dé lugar. Por eso es tan frecuente, casi estructural diremos, la dificultad real de lograr mejoras, y esto en contravía de un Estado para el que la corrupción se convirtió en condición para realizar algún tipo de avance social. Por supuesto, este texto no tiene por objetivo entrar en discusiones justificadoras de tal o cual esfuerzo de organización, y mucho menos de denunciar o justificar cuando de acciones subversivas y terroristas se trata. Pero sí quiere indicar cómo un estado de cosas, para todo un lazo influido por la corrupción, difícilmente puede abandonar sus hábitos, a menos que el cambio sea rotundo en este aspecto. Eso está implicado en cómo pensamos el sujeto supuesto altruista y su objeto beneficiario.

Sin embargo, pensemos por un instante que estas organizaciones (subversivas) surgieron, y su primer impulso, bajo ideologías que prometían un anhelado cambio que nadie quiso asumir políticamente. Esta posición de desconocimiento del otro, del semejante, por parte del Estado y en particular del gobierno y sus instituciones, equivalente a la de los primeros españoles frente a sus hijos, derivó en diversos conflictos que van desde la impostura de apellidos para denotar propiedad privada de esclavistas, pasando por las violentas identificaciones con partidos que bañaron de sangre ciudades y pueblos, hasta las situaciones más complejas que hoy día vive una Colombia que no termina de recuperarse de intereses fragmentados (individualizados), pero todos enfocados en la ganancia económica a como dé lugar, lo que llevó a la perversión generalizada del provecho de las oportunidades.

Esto trae la dificultad, también predominante, de desconfianza en sectores que tienen recursos para poder aplicar mejoras en la calidad de vida, así como en sujetos que prefieren 'poner su grano de arena' por cuenta propia, sin asociarse en un proyecto social, o a una actividad organizada por una institución que posea la labor voluntaria dentro de sus metas. En otras palabras: la corrupción, las diversas dificultades políticas e históricas, que están determinadas en buena parte por intereses económicos, desalientan la inversión de aquellos sectores que pueden bien influir positivamente con $\mathrm{AV}$ organizadas.

Volviendo a las dificultades que encontramos en el caso de las AV están las representaciones sociales arraigadas en las ideas de las personas, y sus comportamientos, que siguen siendo predominantemente equivalentes a los modelos anteriores, en los que los prejuicios de la caridad aún funcionan como fundamento de la $\mathrm{AV}$.

Esto resulta patente en lo sucedido en la naciente Gran Colombia: mientras el gobierno y sus instituciones asumieron administrativa, económica y políticamente de manera muy diferente al Estado frente a lo propuesto monárquicamente, los pensamientos, las conductas y la idiosincrasia de las personas quedó seriamente ligada a los preceptos anteriores, y seriamente a los católicos. Así, las formas de pensamiento arraigados siguieron siendo eficaces y permitieron que las AV permanecieran en la mentalidad de la gente solo en tanto acto caritativo. Aquí existe una clave que la historia permite aclarar y empezar a superar: es preferible superar el acto caritativo para no exigir, en términos de estructura, que las poblaciones continúen en una senda de vulnerabilidad, asistencialismo y falta en responsabilidad frente a su condición.

Teniendo el norte anterior, debemos contar con la permanente tensión entre lo privado y lo público, existente en relación con lo institucional en nuestro país y con los intereses económicos que se evidencian. Para este fin específico, todo, organizaciones y personas interesadas en el tema de las AV debemos recurrir a más conceptos, en particular el de los sectores productivos de la economía, divididos en tres: el primero correspondiente al gobierno y encargado de todo el gasto público; el segundo, las empresas que producen ganancias privadas; y el tercer sector, que es mixto, encargado de enfocarse en acciones sociales mediante la labor que ejercen las ONG. Al respecto, y frente a lo que ha sucedido con todas las organizaciones del 'tercer sector', encontramos que la investigación de Villar (2001), aclara que, para estas instituciones, su nacimiento: 
(...) más que una historia aislada del Estado, de las instituciones públicas y de los partidos políticos, las organizaciones del tercer sector han sido independientes y entrelazadas con las instituciones estatales, permeadas por vínculos ideológicos, flujo de recursos y roles complementarios, conflictivos y suplementarios.

Las relaciones tejidas entre los sectores, pero en especial entre el primero y el tercero, denotan las confluencias históricas que el país ha tenido y sigue forjando. Los más diversos intereses, en los que lo económico prima, están a la orden del día. No se trata de ir más lejos en este texto respecto a cuestiones que se encuentran mucho mejor delimitadas en otros estudios. Lo que queda es pensar el reto del postconflicto con las herramientas arriba adquiridas, dando lugar digno al objeto del beneficio: otro ser humano que debe ser restituido en condición de interlocutor válido, de sujeto de derecho y deberes en un Estado laico.

El reto para el Estado, entonces, es: garantizar el respeto de los derechos de cada colombiana y colombiano, y proteger especialmente a las víctimas del conflicto y a aquellos profesionales, voluntarios o asalariados, que propenden por la restitución de derechos, con todo lo que ello conlleva. Es necesario dejar de pensar en función de acuerdos y documentos que supuestamente aseguran el cumplimiento de dicha condición y empezar a actuar desde la verdadera condición elemental del lazo humano: somos prójimos. No es un reto sencillo, esto implica hacer valer la justicia y propiciar verdaderamente un marco de aplicación de la misma sin los vicios del pasado. Nos queda solo ser optimistas, pero también asumir nuestra parte en tanto ciudadanos que hacemos seguimiento a este tema.

Para las ONG son más puntuales los retos. Los principales deben estar referidos a su verdadero compromiso social, y no económico. A dinamizar eficazmente sus recursos y a lograr que las y los beneficiarios de proyectos sociales puedan superar su condición pasiva ante las dificultades. Por otra parte, si bien se trata de un Estado de derecho, en el que muchas condiciones deben estar a la orden del día para ejercer políticamente decisiones y opciones, es importante la claridad que estas organizaciones tengan respecto a su posición de cara al conflicto y a la solución del mismo, independiente de su 'credo' político, pues siempre encontraremos ligazones, a veces evidentes, otras ocultas, respecto a la dinámica partidista que caracteriza a nuestro país.

El reto también es incluir más profesionales sociales, más personas interesadas en influir positivamente en el cambio social. Esto implica un esfuerzo económico, es cierto, pero aquí es cuando el voluntariado se convierte en una opción. Un primer reto es demostrar procesos transparentes, lo que obliga a las ONG a hacer más visible su labor y sus logros. Cada acción, cada moneda que se invierta en lo social, se retribuirá en mejor calidad de vida, directa e indirecta, siempre que se haga con la experticia de quienes pueden trabajar con las comunidades que lo necesitan. Todo esto deriva en la responsabilidad compartida de los sectores productivos y todos los ciudadanos que participamos del Estado.

Esta parte de la investigación realizada aporta pues, en este punto, el cuestionamiento puntual a las instituciones que reconocen en su misión la caridad, y la contraparte narcisista en individuos que desean hacer procesos de voluntariado sin una motivación verdaderamente humanista o humanitaria. Se genera la necesidad de mejorar varios procesos, y fundamentalmente los de organización de las políticas que rigen a las instituciones que realizan $\mathrm{AV}$, y así reconocer la verdadera necesidad que demandan sea cubierta por las y los voluntarios, quienes deben asumir procesos de selección cada vez más rigurosos y benéficos para su propio crecimiento personal, profesional y dentro de las instituciones.

Ahora, y es el reto para esta investigación que continúa y para otras que visualizan su lugar en el posconflicto del país, la pregunta es: ¿cómo lograrán motivar, el Estado y las ONG, a las y los profesionales para que hagan labor voluntaria, con un verdadero enfoque humanitario y ético en Colombia?

\section{REFERENCIAS}

1. Althousser, L. (1989). Ideología y aparatos ideológicos del Estado. En: La filosofía como arma de la revolución. México: Siglo XXI.

2. Bermúdez, I. Comp. (2009). Castas, Mujeres y sociedad en la independencia. Bogotá: Ministerio de Educación.

3. Bourdieu, P. (1984). La distinción. Madrid: Taurus.
La dificultad

entre la caridad $y$

la filantropía: un

aspecto a revisar en el marco de las acciones voluntarias en Colombia 
4. Crompton, R. (1994). Clase y Estratificación. Una introducción a los debates actuales. Madrid: Tecnos.

5. Espinoza, W. (1980). La sociedad andina colonial. En Historia del Perú, IV. Lima: Juan Mejía Baca Editores.

Pinzón |

6. Forero, H., et al. (2009) Algunas instituciones de atención hospitalaria. En: Momentos bistóricos de la medicina colombiana. Bogotá: Editorial Universidad Nacional de Colombia.

7. Freud, S. (1950/2004). Proyecto de psicología para neurólogos. En: Obras Completas, vol. I. Buenos Aires: Amorrortu.

8. Freud, S. (1927/2004). El porvenir de una Ilusión. En: Obras Completas, vol. XXI. Buenos Aires: Amorrortu.

9. Freud, S. (1930/2004). El malestar en la cultura. En: Obras Completas, vol. XXI. Buenos Aires: Amorrortu.

10. Granda, A., Mejía, H. y Londoño, C. (1994). La juventud de Medellín y la construcción de la democracia. Medellín: UPB.

11. Hobbes, T. (1642/1984). Leviatán o la materia, forma y poder de una república eclesiástica y civil. México: Fondo de Cultura Económica.

12. Hume, D. (1742/1993). Investigación sobre los principios de la moral. Madrid: Alianza.

13. Larrañaga, I. (1981). El hermano de Asís, vida profunda de San Francisco. Lima: Paulinas.

14. Le Brun, J. (2010). El emblema de la caridad. En: El Amor Puro, de Platón a Lacan. Buenos Aires: Ediciones Literales.

15. Madrid, A. (2001). La institución del voluntariado. Madrid: Editorial Trotta.

16. Márquez, J., Casas, Á. y Estrada, V. (dir.). (2004). Higienizar, medicar, gobernar. Historia, medicina y sociedad en Colombia. GIHSA, Universidad Nacional de Colombia-Sede Medellín.

17. Mendoza, M. (2009). Marco conceptual y contextual del voluntariado en Colombia y su relación con el desarrollo económico. Bogotá: DANSOCIAL y Universidad Colegio Mayor de Nuestra Señora del Rosario.

18. Ramírez, M. (2006). De la caridad barroca a la caridad ilustrada. Bogotá: Editorial Universidad Nacional de Colombia.
19. Restrepo, E. (2006). El Hospital San Juan de Dios. En: Recetas de espiritu. Bogotá: Universidad Nacional de Colombia.

20. Restrepo, E. (1997). Historia del archivo de la Compañía de Jesús en Santafé, 1604-1767. En: Anuario Colombiano de Historia Social y de la Cultura, 24.

21. Stiefken, J. (2015). Altruismo y solidaridad en el Estado de bienestar, Tesis doctoral realizada en la Facultad de Sociología de la Universidad de Barcelona. Recuperado de: http://tdx.cbuc. es/bitstream/handle/10803/284047/jpsa1de1. pdf? sequence $=1$.

22. Tavazza, L. (2001). El nuevo rol del voluntariado. Argentina: Lumen, 1995.

23. Villar, R. (2001). El tercer sector en Colombia. Evolución, dimensión y tendencias. Bogotá: Confederación Colombiana de Organizaciones no Gubernamentales.

24. Wright, E. (1983). Clase, crisis y estado. Madrid: Siglo XXI de España.
Volumen 10

Número 20

Enero-Junio |

2017 |

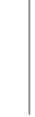

